\title{
«AQUELLA SEGUNDA FÁBRICA QUE HA DE ESTAR EN LO INTERIOR DE LA OTRA»: LOS PROYECTOS DE TABERNÁCULO PARA EL SAGRARIO DE LA CATEDRAL DE SEVILLA Y SU REALIZACIÓN EFÍMERA EN 1662
}

\author{
POR \\ ÁLVARO RECIO MIR \\ Universidad de Sevilla
}

\begin{abstract}
Una vez terminado el Sagrario de la Catedral de Sevilla, se pensó levantar en su cabecera un gran tabernáculo, para el que se barajaron diversos proyectos y materiales. En 1662 la traza elegida, del arquitecto Sebastián de Ruesta, fue realizada de manera efímera con motivo de las grandiosas fiestas de inauguración del templo, acompañándose de esculturas probablemente de Francisco Dionisio de Ribas. El resultado insatisfactorio de la empresa motivó la no realización del tabernáculo definitivo, que se hubiese convertido en el primero del barroco andaluz. A pesar de que no se conservan trazas de la obra, las descripciones manejadas permiten reconstruirlas hipotéticamente. En todo este asunto jugó un papel esencial el mayordomo de fábrica del templo, el canónigo Alonso Ramírez de Arellano, siendo también interesante el análisis de la interpretación de la obra que dio su propio autor, como un edificio dentro de otro.

Palabras clave: Sagrario - Catedral - Sevilla - Tabernáculo - Ruesta - Ribas - Ramírez de Arellano Barroco - Arquitectura - Efímero - Andalucía.

Upon termination of the Sacrarium of Seville Cathedral, there was a plan to construct a large tabernacle at its head, for which various projects and materials were considered. In 1662, the selected design by the architect Sebastián de Ruesta was executed only temporarily in conjunction with the magnificent celebrations organized for the inauguration of the temple, including sculptures probably by Francisco Dionisio de Ribas. The unsatisfactory outcome of this ephemeral construction resulted in the decision not to build the definitive tabernacle, which would have been the first in Andalucian Baroque style. Although the designs for the project have not survived, it is nevertheless possible to reconstruct them hypothetically, based on descriptions of the work. The superintendent and canon of the temple, Alonso Ramírez de Arellano, played an essential role in the planning of this tabernacle. It is also interesting to consider the interpretation of the structure given by its architect as that of a building inside another.

Key words: Sacrarium - Cathedral - Seville - Tabernacle - Ruesta - Ribas - Ramírez de Arellano - Baroque - architecture - ephemeral - Andalucia.
\end{abstract}

Han sido muchos los estudios que en los últimos años se han ocupado del arte festivo del Renacimiento y el Barroco. Asuntos tan sugestivos como sus relaciones con las construcciones permanentes han centrado investigaciones en las que, por lo general, se ha repetido que las 
festivas, por su realización con maderas y telas básicamente, permitían un desarrollo más imaginativo y fantástico que las segundas, condicionadas por la rigidez de su propia materialidad. También se ha indicado que en las empresas festivas, al igual que en los retablos -mundo con el que tanta relación tienen-, sus autores ensayaron tipologías y fórmulas constructivas y decorativas innovadoras que luego, cuando los materiales, la economía y la propia tectónica de los edificios lo permitieron, plasmaron en realizaciones arquitectónicas, y de todo género artístico, de carácter permanente ${ }^{1}$.

No obstante, tales cuestiones responden a una casuística no del todo conocida, al tratarse las festivas de obras en su inmensa mayoría perdidas y de las que tenemos escasas referencias gráficas. Precisamente en estas páginas trataremos un caso que no encaja con las ideas antes aludidas y generalmente aceptadas. Se trata de un tabernáculo para el Sagrario de la Catedral de Sevilla que, trazado e iniciado como obra permanente, a la postre sólo se materializó como una gran empresa festiva, de forma que en esta ocasión fue la arquitectura permanente la que inspiró a la efímera.

Plantearemos además un asunto aún por estudiar y de no fácil tratamiento, que en esta ocasión se justifica por sí mismo, el de la arquitectura dentro de la arquitectura. No son extrañas en pintura las referencias al cuadro dentro del cuadro ${ }^{2}$, pero en relación con la arquitectura esta cuestión ha pasado casi inadvertida. No obstante, apuntaremos este aspecto, ya que así fue entendido el objeto de nuestro análisis por los artistas que participaron en su construcción, que ellos definieron como una «segunda fábrica que ha de estar en lo interior de la otra» ${ }^{3}$.

La otra fábrica, la primera, es el Sagrario catedralicio, el gran empeño artístico del Cabildo durante el siglo xviI. Fue trazado conjuntamente por Miguel de Zumárraga, Alonso de Vandelvira y Cristóbal de Rojas e iniciado en 1618 por el primero, al que le sucedió a su muerte en 1630 Pedro Sánchez Falconete, que cerró sus bóvedas en 1656. A partir de entonces el Sagrario vivió un intenso proceso de enriquecimiento ornamental, como se ve en sus bóvedas, talladas por Pedro de Borja, y en las enormes esculturas de los Evangelistas y Padres de la Iglesia de José de Arce que rematan sus tribunas. Tal aggiornamento decorativo camufló en parte el carácter clásico del edificio, que sigue el modelo renacentista de la iglesia del Hospital sevillano de las Cinco Llagas ${ }^{4}$.

Resulta lógico que, una vez terminado el edificio, el Cabildo pensase levantar en su cabecera un retablo, el cual permitiría agudizar su buscada barroquización. Por ello a principios de 1660 se planteó la cuestión, «atento a ser la obra del Sagrario de las insignes fábricas y más hermosas del orbe y estar oi en tan buen estado que sólo el rretablo del altar mayor i perficionarla falta». Con tal fin se nombró una comisión encargada de reconocer la obra y de asesorarse por «los hombres prácticos en este arte y con su parecer se haga cónputo de los gastos que fuere necessario se hagan» ${ }^{5}$.

\footnotetext{
1 Estos asuntos han sido puestos al día en el catálogo, a cargo de Marcello Fagiolo, La festa a Roma dal Rinascimento al 1870. 2 vols. Turín, Umberto Allemandi \& C. y J. Sands, 1997. Véase también el innovador planteamiento que se hace del asunto en Isabel Cruz de Amenábar, «Arte festivo duradero: un legado permanente». Laboratorio de arte, n. ${ }^{\circ} 10$, pp. 211-231. Sevilla, 1997.

2 Julián Gállego, El cuadro dentro del cuadro. Madrid, Cátedra, 1978. El cuadro dentro del cuadro se convirtió incluso en un género pictórico estudiado en Matías Díaz Padrón y Mercedes Royo-Villanova, David Teniers, Jan Brueghel y los gabinetes de pinturas. Madrid, Museo del Prado, 1992.

${ }^{3}$ Así fue entendido por Sebastián de Ruesta, autor de sus trazas. Véase Teodoro Falcón Márquez, La Capilla del Sagrario de la Catedral de Sevilla. Sevilla, Diputación Provincial de Sevilla, 1977, p. 101.

${ }^{4}$ Teodoro Falcón Márquez, La capilla del Sagrario... op. cit. Mas datos sobre el edificio aparecen en Fernando Cruz Isidoro, «Aparejadores que intervinieron en la construcción de la iglesia del Sagrario de la Catedral de Sevilla». Archivo hispalense, $\mathrm{n}^{\circ}$ 226, pp. 189-209. Sevilla, 1991 y del mismo autor Arquitectura sevillana del siglo XVII. Maestros mayores de la Catedral y del Concejo Hispalense. Sevilla, Universidad de Sevilla, 1997, pp. 38-40 y 71-74.

${ }^{5}$ Archivo de la Catedral de Sevilla (en adelante A.C.S.) Autos Capitulares 1659-1660 (65), fol. 20 vto. de 1660.
}

$A E A, \mathrm{LXXVI}, 2003,301$, pp. 55 a 70 
Conociendo la meticulosidad de los capitulares en todo lo relativo a la dirección de sus empresas artísticas, suponemos que de inmediato se empezarían a barajar las distintas formas que podría tener el retablo y los artífices que podrían levantarlo, que, como solía ocurrir en relación con la Catedral, serían los más prestigiosos de la ciudad. De la igual forma se actuaría para perfeccionar el edificio, en clara referencia a la conclusión de su ornato.

En la primavera de ese año se nombró la demandada comisión, pero ante los rumores de que la iglesia «no estaba conforme a las reglas de arquitectura», al haber aparecido unas grietas en su cabecera, y ante la psicosis de ruina que se apoderó del Cabildo, se acordó que se ocupase sólo de la estabilidad del edificio ${ }^{6}$. De esa forma el asunto del retablo pasó a un segundo plano, ya que la firmeza del templo se convirtió en la única preocupación de los capitulares durante más de un año, en el que buscaron una solución. Las visitas de numerosos arquitectos no hicieron más que aumentar la preocupación capitular ante el carácter contradictorio de sus pareceres. Por fin, en julio de 1661, tras los satisfactorios informes de Juan de Rueda y Juan de Torija, el Cabildo «se daba por satisfecho totalmente del rezelo y duda que se tenía de dicha obra» ${ }^{7}$.

Tal acuerdo reactivó las obras del Sagrario y coincidió con la llegada a la mayordomía de fábrica catedralicia de grandes donativos, como los veinte mil ducados del arzobispo Pedro de Urbina, igual cantidad que la que donara el arzobispo Pedro de Tapia en 1657. Por ello el Cabildo, ansioso de inaugurar el templo, dispuso «determinar que será precisso que se haga (para) colocar a el Santísimo Sacramento en el Sagrario» ${ }^{8}$.

De esta forma se retomó el asunto del retablo, y en agosto de 1661 Alonso Ramírez de Arellano, canónigo y arcediano de Sevilla que entonces desempeñaba la mayordomía de fábrica catedralicia, propuso al Cabildo hacer «el banco del retablo del altar mayor», para «colocar el Santísimo con mucha decencia y authoridad». Tras larga discusión se acordó levantar el banco «conforme al diseño que está en poder del dicho señor arcediano de Sevilla... y que... se adorne para colocar a Nuestro Señor en él y juntamente el camarín donde a de estar su Divina Majestad, todo a disposición del dicho arcediano de Sevilla». Los gastos de tales obras, más los ocasionados por la realización de las puertas y cajoneras de la sacristía del Sagrario y sus confesionarios, los calculó Ramírez de Arellano en nueve mil ducados, para lo cual se pensó aplicar los cuatro mil que había librado el arzobispo como primera entrega de su donación y los donativos capitulares ${ }^{9}$.

El papel de Ramírez de Arellano, que como iremos viendo fue clave en la ornamentación del Sagrario, vuelve a ponerse de relieve en abril de 1662, cuando comunicó al Cabildo que no habían llegado las losas de Génova necesarias para acabar de solar el edificio, asunto del que también se ocupó personalmente, a pesar de lo cual dispuso «que el día de la octava de el Corpus Xristi se coloque y se ponga el Santísimo Sacramento». Ello parece indicar que, debido a la entera confianza que le había mostrado el Cabildo, decidió levantar el banco del retablo y fijar una fecha para la inauguración del templo. No obstante, Ramírez de Arellano vio que para cumplir sus planes no tenía dinero suficiente, habiendo gastado ya cuatro mil ducados y faltando cinco mil de los nueve mil presupuestados. Por ello «se fue al señor arzobispo don fray Pedro de Urbina y le suplicó, que de la donación que a la fábrica tiene hecha, socorriese esta necesidad». El auxilio del prelado se tradujo en la entrega de otros cuatro mil duca-

\footnotetext{
${ }^{6}$ Teodoro Falcón Márquez, La Capilla del Sagrario... op. cit., p. 47 y A.C.S. Autos Capitulares 1659-1660 (65), fols. 31 vto. y 32 de 1660 .

7 A.C.S. Autos Capitulares 1661-1662 (66), fol. 69 vto. de 1661

8 A.C.S. Autos Capitulares 1661-1662 (66), fol. 71 de 1661.

9 Fernando Cruz Isidoro, Arquitectura sevillana... op. cit. P. 74 y A.C.S. Autos Capitulares 1661-1662 (66), fols. 72 y 72 vto. de 1661 .
} 
dos, a los que el Cabildo añadió mil más. Lo más importante es que se acordó que todo «quede dispuesto y concluydo para el día octavo de el Corpus de este presente año como dicho don Alonso Ramírez ofrece», es decir, el 16 de junio de $1662{ }^{10}$.

El proyecto del mayordomo está claro en cuanto al banco del retablo, pero no tanto en lo relativo al camarín, que hace referencia a la habitación existente tras el testero interior del templo, comunicada con el presbiterio y que se pensó usar como reservorio eucarístico ${ }^{11}$. Así, levantando el banco y acondicionando el camarín se tendrían los elementos básicos, altar y sagrario, para el culto, que por el carácter sacramental del templo alcanzaría gran desarrollo en relación a la eucaristía.

Del retablo auspiciado por Ramírez de Arellano tenemos una descripción que indica que se basaba en un «diseño que se había hecho en Flandes» y que la obra «tenía tres haces, una que miraba a la iglesia, y las (otras) dos a los lados hacia la sacristía y altar colateral de la capilla mayor, arrimándose el respaldo al arco que hace (de) camarín, de forma que en el altar de éste y (en) los tres de la capilla mayor, si se quisiera se pudiese a un tiempo decir cuatro misas, y con este fin levantó la bóveda del panteón que está debajo del altar mayor en la proporción que le pareció conveniente, y para ver cómo le salía esta idea, pidió a la Hermandad ejecutasen en el altar aquella planta; y así se hizo y se reconoció ocupaba todo el presbiterio, y no era del intento, con que se enmendó la bóveda, bajándola al plano, como hoy está, que se desechó la traza que había elegido, reconociendo el inconveniente que se seguía» ${ }^{12}$.

Son numerosos los interesantes asuntos que apunta este texto. En primer lugar, vuelve a poner de manifiesto que Ramírez de Arellano fue clave en la última fase constructiva del edificio, hasta el punto que lo creemos la mente rectora de su proceso de barroquización. La documentación de la obra parece indicar que gracias a su labor intermediaria se consiguieron los donativos de los arzobispos Tapia y Urbina, que permitieron concluir y ornamentar el templo. Las palabras de Ortiz de Zúñiga sobre Sagrario son muy significativas al respecto: «Don Alonso Ramírez de Arellano... á quien Dios dotó de magnanimidad generosa para que por su mano se perfeccionase obra tan de su culto y gloria» ${ }^{13}$. Ello es evidente en cuanto al retablo, como indica la descripción recogida, que lo muestra como una empresa personal dirigida sin el concurso capitular, que delegó en él lo relativo al mismo.

En segundo lugar, resulta llamativo que el modelo de este retablo procediese de Flandes. Desde luego el uso de estampas flamencas era una constante en el arte sevillano desde hacía más de un siglo, en relación sobre todo con la pintura, sin que se tengan referencias de su uso directo en la arquitectura ${ }^{14}$. Al tratarse de un proyecto flamenco cabe sospechar que en él tuvie-

${ }^{10}$ Teodoro Falcón Márquez, La Capilla del Sagrario... op. cit. P. 48 y A.C.S. Autos Capitulares 1661-1662 (66), fols. 24 y 24 vto. de 1662 .

1 Resulta llamativo que se denominase a este espacio camarín, término que no se generalizó en Sevilla hasta finales del seiscientos y con una significación no exactamente igual a la que se le dio en esta ocasión. Sobre este término véase Emilio Gómez Piñol, «Camarines estepeños: origen y función». Actas de las III Jornadas de Historia de Estepa, Patrimonio Histórico. Estepa, Ayuntamiento de Estepa, 1999, pp. 625-642.

12 Teodoro Falcón Márquez, La Capilla del Sagrario... op. cit., p. 67, nota 104.

${ }_{13}$ Diego Ortiz de Zúñiga, Anales eclesiásticos y seculares de la muy noble y muy leal ciudad de Sevilla, metrópoli de la Andalucía... 5 vols. Madrid, 1796, vol. 5, p. 113. De esta segunda edición, a cargo de Antonio María Espinosa y Cárcel sobre la príncipe de Sevilla, 1677, existe facsímil, Sevilla, Guadalquivir, 1988.

Hasta ahora lo único interesante que de Ramírez de Arellano conocemos es su labor en el Sagrario. No obstante, quizás si se rastreara su pista se descubriría su participación en otras empresas artísticas, para cuya dirección estaba especialmente dotado.

${ }^{14}$ El empleo de estampas flamencas en la pintura sevillana de la época es sobradamente demostrado en Benito Navarrete Prieto, La pintura andaluza del siglo XVII y sus fuentes grabadas. Madrid, Fundación de apoyo a la historia del arte hispánico, 1998. Por lo que se refiere a la escultura y a la arquitectura fueron más habituales los modelos alemanes, como Durero o Dietterlin.

$A E A$, LXXVI, 2003, 301, pp. 55 a 70 
se algo que ver José de Arce, de dicha nacionalidad y que pudo proporcionar tal modelo e incluso hacer un proyecto para la obra, aunque ello no sean más que hipótesis ${ }^{15}$. En cualquier caso, este dato evidencia las altas miras artísticas de Ramírez de Arellano, que no quedaron circunscritas al ámbito local. No obstante, pudo tambiën pedir opinión sobre dicha traza a maestros sevillanos, lo que es especialmente factible teniendo en cuenta la importancia de la obra.

Pero sin duda lo más interesante del texto transcrito es la descripción que hace del retablo, del que dice en primer lugar que era un tabernáculo de gran desarrollo arquitectónico. Tenía tres frentes principales, hacia el cuerpo de la iglesia y hacia los extremos del crucero, a los que se añadía un cuarto, arrimado al testero el templo. Además su estructura se prolongaba espacialmente en el camarín que había tras él, con el que se comunicaba y en el que se ubicaba un cuarto altar.

La construcción de esta empresa no era una tarea fácil, ya que se indica claramente que habría de alterarse el sepulcro ubicado en la capilla mayor del templo, destinado a los arzobispos Tapia y Urbina. En concreto se especifica que se tendría que levantar su bóveda, seguramente para darle una mayor perspectiva visual al tabernáculo y quizás también para reforzar el enterramiento.

Llama también la atención que Ramírez de Arellano quisiese cerciorarse de la idoneidad de su proyecto, para lo cual pidió a la Hermandad Sacramental del Sagrario que colaborase en la comprobación del efecto que su planta producía en la capilla mayor del templo, que era de amplio desarrollo frontal pero de escaso fondo. Ello parece indicar que el arcediano no estaba del todo seguro de su proyecto y a la vez lo muestra como un mayordomo de fábrica en extremo meticuloso. Tal ensayo puso de manifiesto que el tabernáculo ocupaba toda la capilla mayor, lo que entorpecía el desarrollo de la propia liturgia, causa por la que se desechó su realización definitiva ${ }^{16}$.

Otra fuente de sumo interés sobre el tabernáculo es el informe que del Sagrario realizó el arquitecto Sebastián de Ruesta, maestro mayor del Alcázar. El documento no está fechado, pero debe ser de 1660 o 1661 y estar escrito a raíz de la aparición de las grietas que hicieron dudar de la estabilidad del edificio. En él criticaba la realización de los sepulcros arzobispales en el presbiterio del templo, «por haber de cargar en aquel pavimento el tabernáculo de mármoles y piedras preciosas o de maderas doradas que se ha de hacer, cuya grandeza ha de llenar todo el hueco de aquel arco principal, antes se habrá de macizar aquel entierro haciendo en él unos machones de modo que sirvan por batir de aquella segunda fábrica que ha de estar en lo interior de la otra y de no hacerlo la carga de dicho tabernáculo bastará para hundirlo si no se adquiere» ${ }^{17}$.

Es evidente que Ruesta se refería al proyecto de Ramírez de Arellano, del que especifica que se pensaba realizar de piedra o de madera dorada. La propuesta pétrea resultaba excepcional en la tradición hispalense, por lo que se barajaría la segunda opción, más barata. Sin embargo, hay que recordar que el primitivo Sagrario catedralicio era presidido precisamente por

15 Además de su nacionalidad flamenca, son conocidas las relaciones de Arce con el norte de Europa, véase Esperanza de los Ríos Martínez, «Nuevas aportaciones documentales a la vida y obra de José de Arce en Jerez de la Frontera y en Cádiz». Archivo español de arte, n. ${ }^{\circ}$ 268, pp. 377-390. Madrid, 1994, p. 381. Sí está documentada la participación de Arce en las esculturas del banco de este tabernáculo. Véase Recio Mir, Álvaro: «José de Arce en la catedral de Sevilla y el triunfo del dinamismo barroco en la escultura hispalense». Laboratorio de arte, n. ${ }^{\circ} 15$, en prensa.

${ }^{16}$ El hecho de que el tabernáculo no se adaptase a la cabecera del templo quizás hizo que Ramírez de Arellano se plantease su emplazamiento en el crucero del mismo, siguiendo las disposiciones trentinas, lo que no pasa de ser una hipótesis, que de realizarse hubiese supuesto un hito en el barroco sevillano. Un proyecto que guarda relación con el que estamos tratando fue el que quiso desarrollar el cardenal Arias medio siglo después en la colegiata del Salvador, asunto tratado en Emilio Gómez Piñol, La Iglesia Colegial del Salvador. Arte y sociedad en Sevilla (Siglos XIII-XIX). Sevilla, Fundación Farmacéutica Avenzoar, 2000, pp. 219 y ss.

17 Teodoro Falcón Márquez, La Capilla del Sagrario... op. cit., p. 101. 
un desaparecido tabernáculo de mármol genovés, trazado en 1565 por Hernán Ruiz II y realizado por el italiano Francisco de Carona y por el escultor Bautista Vázquez «el Viejo» ${ }^{18}$.

No es de extrañar que Ramírez de Arellano quisiese concluir de forma espectacular el nuevo Sagrario. Su fábrica se había levantado por entero de piedra, incluso sus elementos decorativos, a diferencia de la tradición constructiva local, basada en el ladrillo, la madera y el yeso, por lo que es posible que pensara realizar el tabernáculo que la iba a presidir también en piedra. La propuesta pétrea incluiría mármoles embutidos, a lo que debe aludir la llamativa referencia a las piedras preciosas. Estas taraceas marmóreas, que también aparecían en el tabernáculo del primitivo Sagrario, se acababan de emplear en el tabernáculo del retablo mayor de la Catedral de Córdoba, concluido en $1655^{19}$, por lo que es posible que en él se inspirase el sevillano. De la misma forma, es factible que tales labores se pensasen combinar con elementos de bronce dorado, algo que se había realizado en el trascoro de la propia Catedral de Sevilla hacía pocos años ${ }^{20}$.

Asimismo, el informe de Ruesta confirma que el retablo era un tabernáculo y que ocuparía todo el presbiterio del Sagrario, llenando su alzado el testero del templo hasta configurar una verdadera iglesia dentro de otra, concepto sobre el que volveremos. Se ocupa también Ruesta de la complejidad constructiva de la empresa, cuya magnitud obligaría a reforzar el pavimento sobre el que había de apoyarse, hasta cegar el panteón arzobispal, ya que, de no ser así, se hundiría.

De este tabernáculo todavía tenemos otras referencias, como la de Ortiz de Zúñiga, en cuyos Anales indica que en 1662 la Hermandad Sacramental del Sagrario, con motivo del breve Sollicitudo omnium Ecclesiarum, favorable a la creencia de la Inmaculada Concepción, pensó organizar unas solemnes fiestas que también celebrasen la inauguración del Sagrario. Para la ocasión decidió levantar un altar efímero en la cabecera de la iglesia siguiendo la «traza que estaba hecha para su retablo principal, (de forma que) se executase como modelo de él, revestido de colgaduras y otros ornatos, con que sirviendo al lucimiento de esta ocasión, sirviese asimismo a reconocer cómo parecia su traza: que si bien esta después no se aprobó, pareciendo que aunque artificiosísima en forma de custodia, carecía de toda la majestad que se deseaba, ahora con lo vistoso de lo revestido, fue máquina de hermosura y gala pomposísima» ${ }^{21}$.

Los datos de Ortiz de Zúñiga cabe contrastarlos y matizarlos cotejando la documentación de la Hermandad Sacramental y de la Catedral. Efectivamente, la corporación eucarística, al conocer el documento pontificio en enero de 1662, se planteó celebrarlo «con todo el aparato y solemnidad mayor que se pudiere, así de prosesión, altar y misa como de fuegos artificiales». Se decidió que tal solemnidad fuese el último domingo de abril y se nombró para ello una comisión en la que destacan Pedro del Castillo y Herrera, tesorero de la Casa de la Moneda, y Bernabé de Escalante, los cuales en gran medida financiarían las fiestas. La Hermandad fue informada por Ramírez de Arellano de que estaba próximo el traslado del Santísimo al nuevo Sagrario, por lo que, para que pudiese celebrar sus actos en él, le propuso retrasarlos hasta entonces, de manera que se «cumplan ambas obligaciones», lo que aceptó la corporación gustosamente ${ }^{22}$.

\footnotetext{
18 José Hernández Díaz, Arte y artistas del renacimiento en Sevilla. Vol. VI. de Documentos para la Historia del Arte en Andalucía. Sevilla, Laboratorio de Arte de Sevilla, 1933, pp. 69-73.

19 Jesús Rivas Carmona, Arquitectura y policromía. Los mármoles del barroco andaluz. Córdoba, Diputación Provincial de Córdoba, 1990, pp. 42-44.

${ }^{20}$ Por otra parte, la disposición del tabernáculo y camarín hispalenses guarda relación con la del retablo mayor de El Escorial. Ambos camarines tienen pareja disposición en planta y alzado, están comunicados con el altar y son transparentes al contar con ventanas en sus testeros. Por ello cabría entender la cabecera del Sagrario como una interpretación de la escurialense, muy conocida gracias a las universalmente divulgadas estampas del monasterio.

21 Diego Ortiz de Zúñiga, Anales... op. cit., vol. 5., p. 159.

22 Archivo de la Hermandad Sacramental del Sagrario de Sevilla (en adelante A.H.S.S.S.), Libro 3. ${ }^{\circ}$ de acuerdos capitulares (1653-1683), fols. 101 vto.-103 vto. Agradecemos al profesor Rafael Ramos Sosa, responsable de este archivo, habernos facilitado su consulta.
}

$A E A$, LXXVI, 2003, 301, pp. 55 a 70 
Por otro lado, Ramírez de Arellano informó al Cabildo de las intenciones festivas de la Sacramental y de que quería celebrarlas en el Sagrario, una vez colocado el Santísimo. Tal pretensión fue apoyada por el mayordomo al exponerla a los demás capitulares y recalcó que de esa forma las celebraciones por el breve y por el estreno del templo no costarían nada al Cabildo. No obstante, indicó también que «no podía el Cabildo excusar hacer siquiera un día de festividad a la dedicación de aquel nuevo templo». Los capitulares permitieron a la Sacramental celebrar sus fiestas en el Sagrario y decidieron hacer una específica por su inauguración con repiques, luminarias y fuegos. Asimismo, mandaron al mayordomo que indicase a los hermanos de la corporación eucarística, no sin cierta mezquindad, «el fabor que el Cabildo les hace». Acordó también prestar a la corporación «lo que necesitaren de esta iglesia sin reservar cosa alguna» ${ }^{23}$.

Ello muestra, además del control absoluto de Ramírez de Arellano sobre todo lo que se iba a realizar, su sibilina manera de actuar, ya que fue él, y no la Hermandad, quien, una vez conocidas las intenciones festivas de ésta, pensó hacer coincidir la celebración del breve y de la inauguración del templo. De esta forma, al permitir a la corporación eucarística estrenar el Sagrario para desarrollar sus celebraciones marianas, ahorró al Cabildo los gastos de las fiestas de ambos acontecimientos. Sin duda su estrategia fue perfecta, quedando todos contentos y apareciendo él como un mayordomo eficientísimo ante los capitulares y ante la Sacramental.

Volviendo a la referencia de Ortiz de Zúñiga, hay que indicar que la documentación de la Hermandad Sacramental muestra como la corporación quiso dejar claro que las fiestas eran una empresa suya y no del Cabildo, por lo que acordó que «el adorno del altar mayor y capillas sea todo por quenta y costa de la cofradía». Por ello cuando la Hermandad de Ánimas, también del Sagrario, le ofreció su colaboración a cambio de usar luego el aparato festivo, la Sacramental le contestó que el altar que se estaba construyendo le quedaría «sin que sea necesario mudar más que la cera y lo propio harán con los altares de las capillas», pero que no requería su ayuda. No obstante, sugería a los hermanos de tal corporación que se ocupasen de la decoración del Patio de los Naranjos, ya que los paramentos de éste se cubrirían con colgaduras y se levantarían cuatro arcos triunfales ante las Puertas Colorada, del Perdón, del Sagrario nuevo y del viejo, en el centro de cada uno de los lados del patio. En las dos primeras aparecerían los escudos del Cabildo y de Sevilla y en las otras dos los retratos de Alejandro VII y de Felipe IV. Asimismo se adornaría la fuente central y se cubriría el patio con toldos. La Hermandad de Ánimas se comprometió gustosa a ello indicando que «además todos los oficiales de dicha cofradía buscarían adornos y bordados para el altar que se está fabricando» ${ }^{24}$.

Un asunto clave indicado por Ortiz de Zúniga es que, en vez de encargar una traza ex profeso para el altar efímero, la Sacramental empleó la del tabernáculo de Ramírez de Arellano. De esta forma se vería el efecto, a manera de ensayo general, que la obra definitiva produciría. Además se dice de nuevo que se trataba de un tabernáculo, del que se señala que tenía forma de custodia, y que su realización efímera, gracias a la decoración que lo revestía, fue satisfactoria, a pesar de que su estructura no alcanzó la majestad deseada, por lo que la obra permanente no se realizó. Por último, es de lamentar que el analista no hiciese una descripción de la obra levantada en 1662 .

Ello lo remedian dos fuentes complementarias: la documentación de la Sacramental y Fernando de la Torre Farfán que dedicó un libro a las fiestas inmaculadistas y de inauguración del Sagrario. Tal publicación fue ofrecida por la Sacramental al Cabildo y patrocinada por

\footnotetext{
${ }^{23}$ A.C.S. Autos Capitulares 1661-1662 (66), fols. 24 vto. y 25 vto. de 1662. Efectivamente, el Cabildo prestó a la Herrmandad Sacramental todo cuanto pidió, incluida la custodia de Arfe, ya que «no pareçe pueda ofrecerse cosa mayor que la estrena del Sagrario nuevo, que tanto se a deseado». Ibidem, fol. 38 vto.

${ }^{24}$ A.H.S.S.S. Libro $3 .^{\circ}$ de acuerdos capitulares (1653-1682), fols. 104 vto. y 105.
} 
Bernabé de Escalante, que vimos en la comisión que organizó las fiestas de la corporación eucarística ${ }^{25}$.

Torre Farfán, en un interesante preámbulo, establece un paralelismo entre el Sagrario «el mejor Palacio de Dios en la Tierra»-, y el fervor mariano de la ciudad, que se desarrollaron entre los mismos años, de la segunda a la séptima década del seiscientos ${ }^{26}$. Por otra parte, elogia al mayordomo de fábrica: «don Alonso Ramírez a cuyas vigilias deverán los siglos tan cultas las vozes de los mármoles, y tan elegantes las almas de los simulacros. Oy su nombre ocupa todos los alientos que pronuncia el bronze después su memoria llegará hasta donde se paren los siglos».

En cuanto al tabernáculo efímero, indica que para su ejecución se trajeron maderas de Cádiz, de la sierra de Segura y «de la Noruega» y que fueron «convocados artífices». «El dibujo fue, desde la inferioridad del zócalo, a la extremidad de la cúpula, devido a la vigilia de Sebastián Roesta, a quien Grecia, y Roma adorarán líneas, y compases, capaz solo de las gubias, y escoplos de Francisco de Ribas, deseados de Ionia, y admirados en Corintho». De esta forma señala Torre Farfán que la traza del altar efímero era de Sebastián de Ruesta, maestro mayor del Alcázar, y que lo realizó el escultor Francisco Dionisio de Ribas. La participación de ambos la confirma la documentación de la Sacramental, que dice del altar que «su planta es la propia que se a de executar en el Sagrario, que está aprobada por el Cabildo que a entregado Sevastián de Ruesta, architecto que hizo el dibujo y que para que mejor se acierte y execute asiste a dicho Sevastián de Ruesta Francisco de Rivas maestro ensamblador hasta que quede formado en madera» ${ }^{27}$.

Ello ratifica que la empresa temporal seguía el modelo de la permanente, la cual había trazado Ruesta y aprobado el Cabildo. Los autos capitulares catedralicios no recogen tal aprobación, por lo que suponemos que se trataría de una elección personal del hábil Ramírez de Arellano, que sustituiría el aludido proyecto flamenco por éste, lo que indica que al menos hubo dos propuestas de tabernáculo. No obstante, es posible también que el maestro mayor del Alcázar hiciese simplemente una interpretación de un grabado flamenco. Por otra parte, es significativo que no se haga referencia alguna al entonces maestro mayor de la Catedral, Pedro Sánchez Falconete, que hubiese sido el encargado lógico de trazar y ejecutar la obra. Sin embargo, todo parece indicar que Ramírez de Arellano lo ignoró, lo que muestra el carácter excepcional de la obra y su dirección personal.

La descripción del tabernáculo de Torre Farfán dice además que «nacía para ser todo retablo, y no perdiendo el intento, crecía para adorarse todo custodia». Continúa indicando que tenía «medidas de gigante», que concreta, igual que la documentación de la Sacramental, en ochenta pies de alto, cuarenta de ancho y veinte de profundidad, unos veintidós, por once y por cinco metros. Torre Farfán también aclara que tenía «forma pyramidal para mausoleo de Dios, y trono de su Madre».

\footnotetext{
${ }^{25}$ Las descripciones que a continuación referiremos aparecen en Fernando de la Torre Farfán, Templo panegírico al certamen poético que celebró la Hermandad insigne del Santísimo Sacramento estrenando la grande fábrica del Sagrario nuevo de la metrópoli sevillana, con las fiestas en obsequio del breve concedido por la Santidad de nuestro padre Alexandro VII al primer instante de María Santísima Nuestra Señora sin pecado original. Sevilla, Juan Gómez de Blas, 1663 , pp. 8 vto.-11 vto. y A.H.S.S.S. Libro 3. ${ }^{\circ}$ de acuerdos capitulares (1653-1682), fols. 106 y 106 vto. Esta última fuente es resumida en Teodoro Falcón Márquez, «Procesión con motivo del estreno de la iglesia del Sagrario. Documento pictórico del entorno de la Catedral de Sevilla en 1662». Laboratorio de arte, n. ${ }^{\circ}$ 12, pp. 143-152. Sevilla, 1999, p. 145.

${ }^{26}$ Sobre la campaña inmaculadista sevillana, que Kendrik denominó the Marian war, véase Ángel Ortega, La tradición concepcionista en Sevilla. Siglos XVI-XVII. Noticias histórico-críticas con motivo de un proyecto de monumento a la Inmaculada Concepción en esta ciudad. Sevilla, San Antonio, 1917; Carlos Ros, La Inmaculada y Sevilla. Sevilla, Castillejo, 1994 y Miguel Ángel Núñez Beltrán, La oratoria sagrada de la época del barroco. Doctrina, cultura y actitud ante la vida desde los sermones sevillanos del siglo XVII. Sevilla, Universidad de Sevilla-Fundación Focus-Agengoa, 2000, pp. 197-221.

${ }^{27}$ La participación de Ruesta y de Ribas ya fue recogida por Ceán, Juan Agustín Ceán Bermúdez, Diccionario histórico de los más ilustres profesores de las bellas artes en España. Madrid, Imprenta de la viuda de Ibarra, 1800. Ad vocem.
}

AEA, LXXVI, 2003, 301, pp. 55 a 70 
Ambas fuentes señalan que la obra, de tres cuerpos, arrancaba de pedestales de jaspe negro y de seis pies de altura, metro y medio. Estos apeos eran seguro el banco del tabernáculo permanente, de forma que la estructura efímera la soportaba el arranque de la definitiva. El primer cuerpo lo estructuraban doce columnas dóricas de dieciocho pies de altura, unos cinco metros, adornadas con telas bordadas y sus capiteles con plumas blancas de avestruz. Estos soportes enmarcaban cuatro arcadas y eran rematados por entablamentos de cuatro pies y medio de altura, algo más de un metro. El espacio que creaba esta estructura lo centró la Inmaculada de Martínez Montañés, conocida entonces como de Molina, hoy llamada la Cieguecita, dispuesta sobre unas gradas «para el adorno de luzes y plata» y lo remató una cubierta plana. En las arcadas laterales se pusieron esculturas de San Ignacio y de San Francisco de Paula, «vestidas de ricos vestidos» y de tamaño natural.

El segundo cuerpo era jónico, también con doce columnas, pero en este caso algo menores, de dieciséis pies, unos cuatro metros y medio. Estos soportes eran dorados y también enmarcaban cuatro arcadas, estando toda la estructura adornada con telas bordadas, flores y velas. Este cuerpo lo centraba «el trono del sol, con la persona de Dios sacramentado». También se indica que el Santísimo, que estaría expuesto permanentemente durante las fiestas, se colocaría sobre unas gradas y que se encontraría la «custodia en la forma que en la Santa Iglesia mayor, sostenida en los dos ángeles de plata». En este cuerpo había además cuatro esculturas, suponemos que en las esquinas, de tamaño natural, de San José, San Pedro, San Luis de Francia y San Fernando ${ }^{28}$. En las arcadas laterales se encontraban otras imágenes de Santo Domingo de Guzmán y San Francisco de Asís, de las que se dice que «sus trages, sin oponerse a la austeridad del instituto, eran de artificiosa jactancia». Este segundo cuerpo lo coronaba una cúpula.

Por fin, el tabernáculo lo remataba un tercer cuerpo, sostenido por seis columnas corintias de doce pies de altura, unos tres metros y medio, y adornado con «oro, plata, telas y pedrerías». En este remate, que no contaba con imágenes, aparecían dos tarjas con emblemas eucarísticos ${ }^{29}$ (Figs. 1 y 2 ).

Lógicamente se adornó también el resto de la iglesia, así en los extremos del crucero se levantaron dos grandes «aparadores» de treinta pies de alto, unos ocho metros y medio, con piezas de plata y de los que también se encargó Ribas ${ }^{30}$. Estos pseudorretablos estaban rematados por ramos de azucenas de forma «que junto con la custodia que se forma en el altar venga a hazer y formar las armas de la Santa Iglesia», claro y generoso homenaje de la Hermandad Sacramental al Cabildo. En el resto del templo se dispusieron retablos en las capillas, brocados y distintos ornamentos en los paramentos, llegando el adorno al exterior del edificio, que fue decorado con «ingeniosíssimos dibuxos, copiados de las estampas admirables de Rubenes», en clara alusión a que se inspiraron en grabados de Rubens de los que no se indica su temática, pero que sería mariana y eucarística. Además, ya vimos que el Patio de los Naranjos también fue transformado ${ }^{31}$.

\footnotetext{
${ }^{28}$ Torre Farfán sitúa estas esculturas en el segundo cuerpo y la documentación de la Hermandad Sacramental en el primero. Ante esta contradicción nos decantamos por la primera disposición, que era la que tenía, por ejemplo, el monumento catedralicio.

${ }^{29}$ Estas descripciones han permitido realizar las reconstrucciones hipotéticas de la planta y el alzado del tabernáculo que presentamos en estas páginas y realizadas por el arquitecto Javier González Ravina, al que agradecemos su brillante trabajo.

${ }^{30}$ De esta habitual forma de ornato festivo, por acumulación de piezas de plata, se conocen ejemplos anteriores y posteriores, véase Reyes Messía de la Cerda, Discursos festivos en que se pone la descripción del ornato e invenciones que en la fiesta del Sacramento la parrochia Collegial y vezinos de Sant Salvador hizieron. Edición de Vicente Lleó Cañal. Sevilla, 1985 y Emilio Gómez Piñol, La Iglesia Colegial del Salvador... op. cit., p. 228 y ss.

${ }_{31}$ Torre Farfán, Fernando de la: Templo panegírico... op. cit., pp. $12-14$ y A.H.S.S.S. Libro $3 .^{\circ}$ de acuerdos capitulares (1653-1682), fols. 106 vto.-107
} 

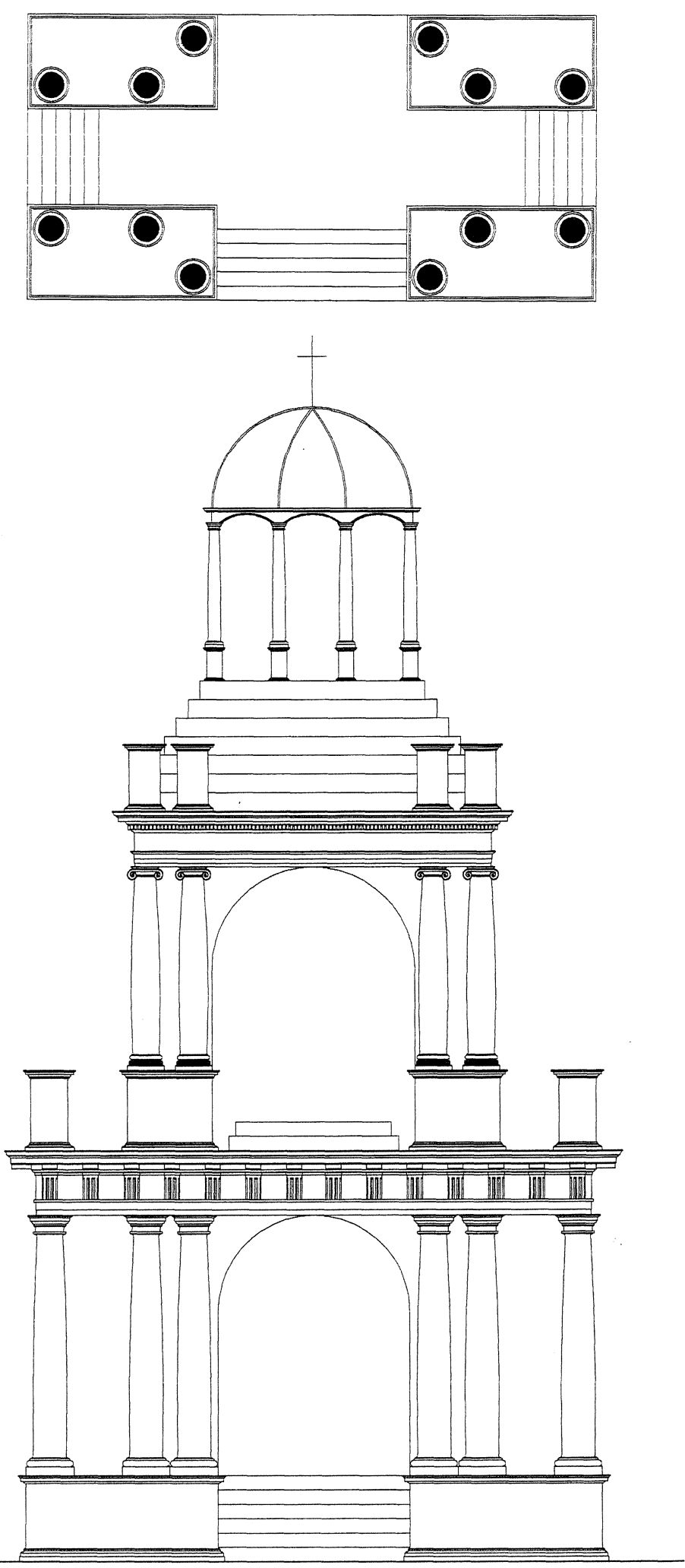

Fig. 1. Planta hipotética del tabernáculo de 1662. Dibujo de Javier González Ravina. Fig. 2. Alzado hipotético del tabernáculo de 1662. Dibujo de Javier González Ravina.

AEA, LXXVI, 2003, 301, pp. 55 a 70 
Aunque el análisis de la fiesta no es el eje de este trabajo, nos parece que estos fastos de 1662 , que pese a su importancia son prácticamente desconocidos, fueron el antecedente de otras dos celebraciones igualmente espectaculares de la Sevilla barroca: la consagración de la iglesia de Santa María la Blanca en 1665 y la canonización de San Fernando en $1671{ }^{32}$.

De los autores del tabernáculo del Sagrario, Ruesta y Ribas, hay que resaltar su significación en la Sevilla de la época. Ruesta, «arquitecto en las obras y fábricas de madera», se había formado en Zaragoza, donde colaboró en dos túmulos levantados en honor del príncipe Baltasar Carlos en 1646. Una vez en Sevilla, fue maestro mayor del Alcázar entre 1650 y 1669 e intervino en otras obras de arquitectura efímera, como el túmulo que se levantó en 1661 en la Colegiata de Olivares para las honras fúnebres del Marqués del Carpio. No extraña que con tal experiencia se le encargase la traza del tabernáculo del Sagrario, cuando además había hecho informes para este edificio ${ }^{33}$.

Por su parte, Ribas era entonces el más destacado retablista y escultor de la ciudad. Al fallecer su hermano Felipe en 1648 y Montañés en 1649 asumió los más importantes encargos de los años cincuenta y sesenta, hasta que hacia 1670 alcanzaron la primacía Bernardo Simón de Pineda y Pedro Roldán ${ }^{34}$. En esos momentos sólo otro escultor y retablista pudo hacerle sombra a Ribas, el ya citado José de Arce ${ }^{35}$.

Sobre la tipología del tabernáculo hay que indicar que contaba con antecedentes en la ciudad, como el referido del Sagrario viejo. De haberse realizado el de Ramírez de Arellano habría supuesto un hito en el barroco sevillano y seguramente se habría convertido en modelo de otros tabernáculos, tipología que en Sevilla no alcanzó un gran desarrollo, a diferencia de lo que ocurrió en otras ciudades de Andalucía. En cualquier caso, el del Sagrario nuevo fue el primer gran tabernáculo barroco proyectado en Andalucía ${ }^{36}$.

Desde luego no había tipología edilicia más adecuada para un recinto sacramental, ya que el tabernáculo refiere el lugar en el que los judíos guardaron el Arca de la Alianza y en el que Jehová quiso residir. Los comentaristas bíblicos le dieron un triple simbolismo: santuario, lugar de reunión y de testimonio ${ }^{37}$. Ello, así como el carácter eucarístico de la obra y la mímesis

${ }^{32}$ Sobre dichas celebraciones remitimos a Fernando de la Torre Farfán, Fiestas que celebró la iglesia parrochial de Santa María la Blanca, capilla de la Santa Iglesia Metropolitana, en obsequio del nuevo breve concedido por nuestro santísimo padre Alexandro VII a favor del purísimo mysterio de la Concepción sin culpa original de María Santísima nuestra Señora, con la circunstancia de averse fabricado de nuevo su templo para esta fiesta. Sevilla, Juan Gómez de Blas, 1666 y del mismo autor Fiestas de la Santa Iglesia Metropolitana, y Patriarcal de Sevilla, al nuevo culto del señor rey San Fernando el tercero de Castilla y León. Sevilla, Viuda de Nicolás Rodríguez, 1671. De esta última obra hay edición facsímil, Sevilla, Focus, 1984. En la primera obra se hace referencia al empleo de estampas de Rubens y de plumas de avestruz como adorno, igual que en el Sagrario, véase la p. 12 vto.

${ }^{33}$ Sobre Ruesta véase Ana Marín Fidalgo, El Alcázar de Sevilla bajo los Austrias. 2 vols. Sevilla, Guadalquivir, 1990. Vol. $2 .^{\circ}$, pp. 601-608. Los informes referidos al parecer no habían sido atendidos, como indica su autor en el que anteriormente hemos en parte transcrito, en el cual dice: «he dado algunos pareceres por haberlos mandado vuestra señoría sobre el ajuste de algunas medidas y adornos de que se compone dicha fábrica y no se ha hecho aprecio dellos». Teodoro Falcón Márquez, La Capilla del Sagrario... op. cit., p. 99. Por el contrario, en relación con el tabernáculo, sí se siguieron sus indicaciones.

${ }^{34}$ Sobre Ribas remitimos a María Teresa Dabrio González, Los Ribas. Un taller andaluz de escultura del siglo xviII. Córdoba, Monte de Piedad y Caja de Ahorros de Córdoba, 1985. En cuanto al retablo sevillano de ese momento véase Fátima Halcón, «El retablo salomónico», en Fátima Halcón; Francisco Herrera y Álvaro Recio, El retablo barroco sevillano. Sevilla, Universidad de Sevilla-Fundación El Monte, 2000, p. 3 y ss.

${ }^{35}$ Ruesta y Ribas volvieron a colaborar en obras significativas, como el retablo de la Capilla de los Vizcaínos del Convento de San Francisco o la Capilla de la Maestranza de Caballería del Convento de Regina Angelorum, que prueba la compenetración alcanzada por ambos. Cfr. Dabrio González, María Teresa: Los Ribas... op. cit., pp. 165,431 y 439.

${ }^{36}$ Sobre los tabernáculos barrocos de Andalucía véase Jesús Rivas Carmona, «Los tabernáculos del Barroco andaluz». Imafronte, n. ${ }^{\circ}$ 3-4-5, pp. 157-186. Murcia, 1987-88-89. Este interesante artículo indica que el primer tabernáculo barroco de Andalucía fue el proyectado para la Catedral de Málaga en 1663, por lo tanto posterior al del Sagrario sevillano.

${ }^{37}$ Sobre el concepto de tabernáculo remitimos a F. Carbol y H. Leclercq, Dictionnaire d'archéologie chrétienne et de liturgie. París, 1953. Ad vocem; Enciclopedia universal ilustrada europeo-americana. Madrid, Espasa-Calpe, 1958. Ad vocem; André Marie Gerard, Diccionario de la Biblia. Madrid, Anaya, 1995. Ad vocem y Dios arquitecto. J. B. Villalpando y el Templo de Salomón. Madrid, Siruela, 1995. Especialmente las pp. 307-320.

AEA, LXXVI, 2003, 301, pp. 55 a 70 
del viejo Sagrario, pudo llevar al mayordomo de fábrica a elegir un tabernáculo para presidir el nuevo Sagrario.

Por otra parte, las descripciones del tabernáculo manejadas nos hacen sospechar que pudo inspirarse en el monumento eucarístico de la Catedral de Sevilla, realizado por Asensio de Maeda a finales del siglo XVI ${ }^{38}$. Las similitudes entre las descripciones del tabernáculo del Sagrario y el monumento son notables, coincidiendo en que su alzado se articulaba en tres cuerpos, en su impronta clásica y en la distribución de sus esculturas. No obstante, suponemos que la obra efímera tendría un más acusado carácter barroco por la rica decoración que la cubría.

El espíritu clásico del tabernáculo debía responder a la concepción que de la arquitectura tenía su autor, Sebastián de Ruesta. Éste, en el referido informe sobre el Sagrario, parece poner en evidencia su apego a la tradición clásica, manifestando su oposición a la corriente barroca de signo decorativo que empezaba a proliferar en Sevilla. De esta forma, criticó el enriquecimiento ornamental del templo, que no aparecía en sus trazas originales ${ }^{39}$. Por el contrario, Ribas se había decantado ya por el barroco salomónico, que plasmó en sus retablos de los años sesenta y setenta, pero no en el tabernáculo del Sagrario, del que sólo fue ejecutor material.

La aludida relación del monumento con el tabernáculo nos hace sospechar que quizás los dos primeros cuerpos de este último tendrían planta de cruz griega inscrita en sendos rectángulos. De tal forma las doce columnas de cada cuerpo se agruparían de tres en tres y permitirían la disposición en sus ángulos de las imágenes referidas. En cambio, el tercer cuerpo, de seis soportes, lo suponemos circular, en contraste con los anteriores. Es muy posible también que buena parte de los elementos de esta estructura fueran del propio monumento, cuyas piezas sabemos que se empleaban en las fábricas efímeras que con frecuencia se levantaban en la Catedral, lo que es especialmente factible en este caso por la aludida colaboración del Cabildo con la Sacramental.

No obstante, y volviendo al posible origen flamenco de la traza del tabernáculo, hay que indicar que su configuración, de frente amplio y escaso fondo para adaptarse a la cabecera del templo, recuerda a las tipologías retablísticas del norte de Europa, en especial de Flandes. Así, cabe citar el flügel-altar germano o altar volante. Pero sin duda, son los retablos flamencos los que más recuerdan al tabernáculo del Sagrario. En Flandes alcanzó gran predicamento un tipo de retablo mayor de amplio desarrollo frontal y escasa profundidad, que se disponía cerca pero no anclado a la pared. A lo largo del siglo XVII este tipo de obras fue adquiriendo mayor profundidad y autonomía respecto a las cabeceras de los templos, hasta que al final de la centuria se convirtieron en tabernáculos exentos de planta circular, elíptica y, sobre todo, rectangular ${ }^{40}$. Es posible, por tanto, que el ejemplo sevillano se inspirase en un grabado de alguno de ellos.

También cabe vincular el tabernáculo con la custodia de Arfe, cosa que ya hizo Torre Farfán. La citada custodia estaba representada frente al emplazamiento del tabernáculo, en la vidriera que cierra la ventana de los pies del templo, de forma que tal pieza litúrgica se convirtió en un verdadero icono, casi en un objeto de culto en sí mismo. En relación con el tabernáculo, además de su estructura arquitectónica, cabe destacar su paralelismo iconográfico. En ambos casos era el segundo cuerpo el eucarístico, mientras el inferior en la obra del Sagrario era mariano, como sería en la custodia tras su reforma de 1668. En cualquier caso, la estructura e iconografía del tabernáculo eran un canto triunfal a la Eucaristía y a la Inmaculada.

Otro hecho significativo es que se levantase tan opulenta obra en un momento de especial depresión en la ciudad. En este sentido resulta llamativo que al morir el príncipe Baltasar Car-

\footnotetext{
${ }^{38}$ El monumento es estudiado en Vicente Lleó Cañal, «El monumento de la catedral de Sevilla en el siglo xvi». Archivo hispalense, n. ${ }^{\circ}$ 180, pp. 97-111. Sevilla, 1976.

${ }^{39}$ Teodoro Falcón Márquez, La Capilla Sacramental... op. cit., pp. 99-107.

${ }^{40}$ Véase Hans Vlienghe, Arte y arquitectura flamenca 1585-1700. Madrid, Cátedra, 2000, p. 363.
} 
los en 1646 el Cabildo no hizo más que un sencillo estrado. Lo mismo ocurrió veinte años después al fallecer Felipe IV, a pesar de que se realizaron varias trazas para levantar un gran túmulo ${ }^{41}$. Hay que recordar además que en ese momento Sevilla todavía vivía las secuelas de la peste de 1649, de la guerra con Francia y que aún se encontraba muy implicada en la guerra con Portugal ${ }^{42}$.

Ello contrasta con la máquina levantada en 1662 en el Sagrario, de evidente magnificencia y buen ejemplo para calibrar la Sevilla barroca, en la que las hermandades jugaron un papel preponderante, en ocasiones por encima de importantes instituciones como el Cabildo catedralicio. También pone esta obra en evidencia la efusión mariana de la ciudad, que lideró una verdadera cruzada en defensa de su concepción inmaculada. No es de extrañar por tanto que, una vez ganada tan singular contienda gracias al breve en 1662, lo celebrase cómo ninguna otra ciudad del mundo ${ }^{43}$.

La empresa que tratamos no era solamente arquitectónica, jugando en ella un gran papel la escultura, a pesar de lo cual la documentación nada dice sobre la autoría de las ocho imágenes del tabernáculo. Es lógico pensar que fuese Ribas el autor de estas obras, de las que se indica que eran maniquíes, lo que permitiría su rápida ejecución, que en gran parte realizarían los muchos auxiliares que sabemos que tuvo. Las caras y manos esculpidas se unirían a candeleros recubiertos de lujosas telas, lo que animaría la arquitectura del tabernáculo y reforzaría su sentido decorativo y barroco, además de completar su iconografía que centraban la Inmaculada y el Santísimo Sacramento.

Estas imágenes, mas que configurar un programa iconográfico, parece que acompañaban a la Virgen y la Eucaristía, ya que las descripciones consultadas no hacen referencia a los habituales textos latinos que solían articular los complejos programas de las estructuras efímeras, por lo que en este caso no existirían. De esta forma el tabernáculo se completó con una serie santos, que debían manifestar devociones populares más que alambicadas disquisiciones de carácter teológico.

Por otra parte, la documentación de la Hermandad Sacramental indica que para trasladar la Inmaculada de Montañés de su capilla de la Catedral al Sagrario se hizo un enorme carro «en forma de nave», de trece metros de largo, cuatro de ancho y cinco y medio de alto, del que fue autor Pedro de Borja. Pero lo que más nos interesa ahora es que en la parte delantera del mismo aparecían las figuras de Adán, Abraham, David y una culebra y en la trasera los cuatro papas que habían auspiciado la devoción concepcionista: Sixto IV, Paulo V, Gregorio XV y Alejandro VII ${ }^{44}$. Dicha fuente especifica que «la composición del dicho carro era de unas cortezas que formaban sus roleos rebestidos de plata y azul con sus adornos, mascarones y ojas», descripción que cabría aplicar a cualquiera de las yeserías realizadas por Borja ${ }^{45}$.

${ }^{41}$ José M. Baena Gallé, Exequias reales en la Sevilla en la Catedral de Sevilla durante el siglo xvir. Sevilla, Diputación de Sevilla, 1992 y del mismo autor «En torno a las exequias de Felipe IV en Sevilla». Laboratorio de arte, n. ${ }^{\circ} 8$, pp. $385-$ 392. Sevilla, 1995.

${ }^{42} \mathrm{La}$ documentación catedralicia hace referencia a las rogativas que se hicieron «por las paces con Francia» y por el «eliz suceso de sus católicas armas (en referencia a las de Felipe IV) que se hallan dentro de Portugal». A.C.S. Autos Capitulares de $1659-1660$ (65), fol. 45 de 1660 y 1661 (66), fol. 63 vto. de 1661 .

${ }^{43}$ Son pocas las referencias que se tienen a las celebraciones en otros lugares del breve de Alejandro VII. Resulta significativo que en Roma no se celebrase, La festa a Roma... op. cit. Vol. 2. ${ }^{\circ}$, p. 160 y ss. En España Alenda y Mira sólo recoge las fiestas de Valencia, en las que hubo toros y cañas y carros alegóricos, Jenaro Alenda y Mira, Relaciones de solemnidades y fiestas públicas de España. Madrid, Sucesores de Rivadeneyra, 1903. P. 375 y Rafael Ramos Sosa, Arte festivo en Lima virreinal (siglos XVI-XVII). Sevilla, Junta de Andalucía, 1992, pp. 249 y 250. En otras ciudades españolas e hispanoamericanas se registran fiestas inmaculadistas en 1662, pero sin la fastuosidad de las sevillanas, Teodoro Falcón Márquez, La Inmaculada en el arte andaluz. Córdoba, Caja Sur, 1999, p. 13 y Rafael Ramos Sosa, Arte festivo... op. cit., p. 255.

44 Teodoro Falcón Márquez, «Procesión con motivo del estreno...» op. cit., p. 146.

${ }^{45} \mathrm{El}$ carro tenía además ocho tarjas que enmarcaban pinturas marianas. A.H.S.S.S. Libro $3 .^{\circ}$ de acuerdos capitulares 1653-1682, fol. 107. 
No indica la documentación la autoría de las esculturas del carro, que suponemos maniquíes vestidos y que pudieron ser realizadas tanto por Borja como por Ribas ${ }^{46}$. En cualquier caso, destaca la estrecha relación existente entre la escultura y la arquitectura en estas fiestas, así como la importancia de la ornamentación. Ello evidencia una nueva sensibilidad decorativa plenamente barroca, la misma que se desarrolló en la ornamentación del Sagrario y en otras obras como la Iglesia de Santa María la Blanca, transformada con motivo del breve de Alejandro VII.

Pasadas las fiestas, se desmontó el tabernáculo y los decorados levantados para la ocasión, pero las obras del tabernáculo definitivo nunca se retomaron. Entre los motivos que ocasionaron tal abandono ya citamos los espaciales, ya que al ocupar toda la cabecera complicaba el desarrollo de la liturgia, lo que es fácilmente demostrable comparando las medidas del tabernáculo y de dicha cabecera. Por su parte, Ortiz de Zúñiga aludía a que su estructura no alcanzaba la majestad deseada. Además Ruesta apuntó su temor a que agravase los problemas de estabilidad del edificio e indicó que para su realización habría que cegar el panteón de su cabecera. Por otra parte, no hay que olvidar el factor económico, sobre todo para realizar una obra de mármol. Recordemos que, en un ambiente general de ruina, el Cabildo fue incapaz de terminar el Sagrario, por lo que dependió de las donaciones arzobispales, que no serían suficientes para levantar el tabernáculo ${ }^{47}$.

En cualquier caso, la documentación catedralicia especifica que fue el propio Ramírez de Arellano el que renunció a continuar la obra. En enero de 1663 informó al Cabildo de los «muchos inconvenientes de proseguir en el quadro questá empezado en el altar mayor, del costo grande que proseguirle tendrá, que assí mesmo no zería obra de lucimiento». Ante ello los capitulares acordaron no continuar el tabernáculo y que en otra reunión se discutiese «la proposición del arcediano de Sevilla», lo que parece indicar que Ramírez de Arellano tenía nuevas propuestas ${ }^{48}$.

A los pocos días se trató «la disposición y nueva forma con que se avía de hazer el retablo para el altar mayor del Sagrario», una vez «desbaratado el banco que oi está hecho». Tras larga discusión, el Cabildo acordó que el arcediano, «con asistencia de los maestros que le parecieren más a propósito y de más seguridad en esta materia», se encargase de buscar una traza para la nueva obra. Además, indicó «que no se execute ni aga obra alguna sin primero dar cuenta al Cabildo» ${ }^{49}$. De esta forma, a diferencia de lo ocurrido hasta entonces, los capitulares mostraron su interés en intervenir en la obra, aunque sin retirar su confianza en Ramírez de Arellano.

Éste mostró en febrero de 1663 «un diseño para la forma del plano del retablo que se a de hazer para el altar mayor del Sagrario nuevo y el Cabildo mandó se execute en la forma que a dicho señor le pareciere». Asimismo, se acordó que los capitulares, una vez comprobada la traza y su adaptación al marco, se reuniesen «para determinar si se proseguirá» ${ }^{50}$.

Nada más se dice de tal proyecto, pero sospechamos que pudo tratarse de otro tabernáculo, que sería el tercero propuesto. A tal hipótesis nos conduce el hecho de que, al parecer, lo que

\footnotetext{
${ }^{46}$ La documentación de la Hermandad Sacramental sólo recoge los gastos totales de las fiestas inmaculadistas-sacramentales, 68.440 reales de vellón, sin hacer un desglose de los mismos. A.H.S.S.S. Libro $3 .^{\circ}$ de acuerdos capitulares $1653-1682$, fol. 115 vto. y Libro de Mayordomía 1645-1687, fol. 225 vto.

${ }^{47}$ De igual forma se abandonó otra interesante empresa marmórea pocos años después, el retablo para la Virgen de los Reyes trazado por Bernardo Simón de Pineda. Véase al respecto Alfonso Pleguezuelo Hernández, «Un proyecto de Bernardo Simón de Pineda para la Capilla Real». Boletín del seminario de arte y arqueología, n. ${ }^{\circ}$ 47, pp. 335-342. Valladolid, 1981.

48 A.C.S. Autos Capitulares 1663-1664 (67), fols. 7 y 7 vto. de 1663.

49 A.C.S. Autos Capitulares 1663-1664 (67), fol. 8 vto. de 1663

${ }^{50}$ A.C.S. Autos Capitulares 1663-1664 (67), fols. 12 y 12 vto. de 1663.
}

$A E A$, LXXVI, 2003, 301, pp. 55 a 70 
se mostró del mismo al Cabildo fue su planta, que de corresponder a un retablo parietal hubiese tenido poco sentido. En cambio, si lo proyectado era un tabernáculo resulta lógico que para su aprobación se comprobase su adaptación al espacio para el que estaba destinado, no se fuese a repetir lo ocurrido con la obra anterior.

En cualquier caso, el proyecto se debió abandonar enseguida ya que las fuentes catedralicias omiten toda referencia posterior al mismo. Es más, se acordó explícitamente que las gradas del altar mayor «se queden en la forma que están», lo que sugiere que se abandonó la idea de alterar la cabecera del templo. No obstante, se encargó a Ramírez de Arellano que se ocupase del adorno del camarín, que se acordó aderezar «con toda dezencia dejando (en él) un altar en forma de oratorio». De esta forma, cuando no se pudiesen administrar los sacramentos desde el altar mayor, «fin principal para que se a labrado tan suntuoso templo», se haría desde allí ${ }^{51}$.

La causa que haría olvidar definitivamente el tabernáculo fue la finalización en 1663 del empleo de mayordomo de fábrica por parte de Ramírez de Arellano, el impulsor de la idea, que al no realizarse dejó la enorme cabecera del templo llamativamente vacía. Ello se solucionó durante las fiestas por la canonización de San Fernando en 1671 gracias a un interesante retablo efímero. No obstante, tras los fastos fernandinos la ausencia de uno permanente fue de nuevo notoria, lo que señaló Ortiz de Zúñiga de forma significativa: «Está también desnudo su excelso testero esperando el retablo, que habiendo de ser competente a tanta majestad, requiere no breve premeditación en su forma y su materia» ${ }^{52}$. Ello parece aludir a las referidas dudas sobre su realización y materialidad, así como a la complejidad de elegir una traza definitiva. Lo cierto es que el testero estuvo medio siglo vacío, hasta que Jerónimo Balbás a comienzos del siglo xviII lo llenó levantando en él, y aún más allá de él, el más aparatoso retablo del barroco hispánico ${ }^{53}$.

Para terminar, queremos abordar la significación del tabernáculo, sobre la que ya apuntamos que sus artífices lo entendieron como un edificio dentro de otro. Tal interpretación, que hacemos nuestra, quizás deba relacionarse con el término tabernáculo, que ya indicamos aludía al lugar en el que los judíos guardaron el Arca de la Alianza, función paralela a la de la obra que estudiamos, guardar y exponer las especies eucarísticas. En cualquier caso, si entendemos por edificio la definición de un espacio, este tabernáculo fue un edificio, pero a su vez ocupó parte de otro, el Sagrario. En tal sentido entendemos la idea de la arquitectura dentro de la arquitectura, que, no obstante, es una contradictio in terminis, ya que el espacio al ser ocupado desaparece. El ejemplo más emblemático de este tipo de problemas arquitectónicos es el de San Pedro de Roma, primero en relación con la tumba de Julio II y con posterioridad con el baldaquino de Bernini ${ }^{54}$.

\footnotetext{
51 A.C.S. Autos Capitulares 1663-1664 (67), fols. 42, 44 vto. y 45 de 1663.

52 Véanse respectivamente: Fernando de la Torre Farfán, Fiestas de la Santa Iglesia Metropolitana... op. cit., p. 216 y ss. y Diego Ortiz de Zúñiga, Anales... op. cit., vol. 5, p. 155. En la obra de Torre Farfán aparece un grabado de ese retablo efímero, que fue asociado por Juan Miguel Serrera a Ribas y en el que intervino Murillo, que permite contemplar los aparadores o pseudoretablos levantados por acumulación de piezas suntuarias, básicamente de plata, que de nuevo se realizaron en el crucero del Sagrario en 1671, entonces en forma de águilas bicéfalas. Sobre esta obra véase Juan Miguel Serrera, «Sevilla: imágenes de una ciudad», en Alberto Oliver; Juan Miguel Serrera y Javier Portús, Iconografía de Sevilla 16501790. Madrid, El Viso, 1989, p. 101 y Paulina Ferrer Garrofé, «Murillo escenógrafo: decorado y puesta en escena de la capilla del Sagrario para las fiestas de canonización de San Fernando». Archivo hispalense, n. ${ }^{\circ}$ 195, pp. 76-89. Sevilla, 1981.

53 Sobre el retablo de Balbás y los que le sucedieron véanse Gómez Piñol, Emilio: «Entre la norma y la fantasía: la obra de Jerónimo Balbás en España y México». Temas de estética y arte, n. ${ }^{\circ}$ 2, pp. 95-129. Sevilla, 1988. Pág. 100 y ss. y Serrera, Juan Miguel: «Los ideales neoclásicos y la destrucción del barroco. Ceán Bermúdez y Jerónimo Balbás». Archivo hispalense, n. ${ }^{\circ} 223$, pp. 135-159. Sevilla, 1990.

${ }^{54}$ Otros ejemplos significativos se podrían poner a este respecto, como la Santa Casa de Loreto y sus numerosas reinterpretaciones, pero sin duda el caso más interesante es el de San Pedro. Acerca de la tumba de Julio II véase Christoph L.
} 
En el caso sevillano, ya vimos que parece que fue la conflictiva relación entre ambos edificios la principal causa que provocó que no se levantase el interior. Se vio difícil la adaptación del tabernáculo a la cabecera del Sagrario, que hubiese quedado colapsada por el edificio interior. Cabe interpretar este problema como el temor de que esa segunda fábrica que ha de estar en lo interior quedase presa por la otra y que la funcionalidad de ésta fuese menoscabada por aquella.

Al ser en el barroco cuando la tipología del tabernáculo, a pesar de su larga tradición, alcanzó su apogeo, cabe interpretar este fenómeno de la arquitectura dentro de la arquitectura como especialmente barroco, e igual que en El Quijote se puede hablar del libro dentro del libro, en Hamlet del teatro dentro del teatro, en obras de Haendel y de Mozart del concierto dentro del concierto y de la ópera dentro de la ópera ${ }^{55}$, creemos que el tabernáculo que se pensó levantar en el Sagrario de la Catedral de Sevilla hubiera sido un edificio dentro de otro.

Frommel: «San Pietro», en Rinascimento da Brunelleschi a Michelangelo. La rappresentazione dell'architettura. Milán, Bompiani, 1994. Pp. 399-423 y sobre el baldaquino Irving Lavin, Bernini and the crossing of Saint Peter's. Nueva York, New York University Press, 1968.

${ }^{55}$ Julián Gállego, El cuadro dentro del cuadro... op. cit., pp. 140-142.

AEA, LXXVI, 2003, 301, pp. 55 a 70 